\title{
One Case Study Of Organizational Commitment's Influence Factors Based On Sandplay
}

\author{
Chen Zhenyu \\ Panyapiwat Institute of Management, Thailand \\ email:61751696@qq.com, \\ ${ }^{*}$ Corresponding author: Chen Zhenyu
}

\begin{abstract}
Keywords: Analytical psychology theory; Grounded orientation; Sandplay; psychological complex; Mechanism model of organizational commitment
\end{abstract}

\begin{abstract}
Objective: Analyzed the influence of psychological complex on surface factors of organizational commitment and organizational commitment. Method: The intensity sampling method was used to select a case with multiple resignation experiences, Sandplay was used as a tool to conduct psychoanalytic interviews, and used the qualitative analysis method to encode the data. Result: Psychological complexes were actually deep factors affecting organizational commitment. Psychological complexes had influence on surface factors, but there are differences. Conclusion: The relationship model between surface factors and complex factors of organizational commitment and the two-dimensional model of complex factors of organizational commitment are the most important components of the mechanism model of influencing factors of organizational commitment. This model confirms the deep psychological mechanism that affects organizational commitment from the perspective of psychoanalysis, provides a theoretical basis for the construction of organizational behavior management strategies for individuals, provides a preliminary theoretical framework for subsequent related research, and also provides a theoretical basis for organizations to retain talents.
\end{abstract}

\section{Introduction}

The concept of organizational commitment was first proposed by American sociologist Becker[1]: Organizational commitment refers to a psychological phenomenon that employees wish to remain in the organization as they increase their commitment to organizational time, diligence, and feelings. It is a psychological contract that encourages employees to continue their professional behaviors[2]. The influencing factors of organizational commitment are also called antecedent variables of organizational commitment, which refer to various factors that have positive or negative effects on organizational commitment. these factors are generally divided into organizational characteristics, work characteristics and personal characteristics[3]. Because the structure of organizational commitment has theoretical differences from one dimension to five dimensions, the influencing factors of organizational commitment also become complicated with the change of its structure. Although the definition of organizational commitment has changed to some extent with the passage of time, the " psychological phenomenon that employees want to remain in the organization" should be the core content of all these definitions[4]. In the previous definition statements about organizational commitment, the description of its psychological attributes is also the main one, such as " psychological phenomenon", " attitude", " psychological contract", " sense of dependency", " will", " sense of identity", " normative pressure", " behavior" and so on. However, due to the fact that the concept of organizational commitment is located in the field of economic science from the very beginning, the focus of its research is more on economic activities ( e.g. social exchange), thus the research on organizational commitment is rarely carried out purely from the perspective of psychology. Such research bias will inevitably lose the accuracy and correctness of psychology as the most complicated research object in nature and society - people, especially its more complicated research part. Therefore, from the perspective of reductionism, it is of great significance to put organizational commitment, a psychological variable, into the individual's cognitive, emotional, and volitional activities, and to reconsider, position, and study it from the perspective of cognitive science. 
Similarly, the analysis and research on the influencing factors of organizational commitment can only obtain the first-hand real materials from the above-mentioned standpoint. only by analyzing the research thinking of combining rooted spirit with psychological analysis can we restore the true face of the most complicated research object, individual psychology.

The earliest scholars who studied the influencing factors of organizational commitment found that there are four types of influencing factors of organizational commitment: (1)Personal characteristics, including age, qualifications, educational level, gender, race and personality traits; (2)Relevant role characteristics, including scope of work and challenges, role conflicts and role confusion, etc. (3)The characteristics of the structure include organization scale, trade union involvement, control range, formalization, decentralization degree, decision-making participation degree, etc. (4)Working experience, including organization's dependency, personal importance, expected level, group norms, etc.[5]. Later, some scholars carried out meta-analysis of the research results on the influencing factors of organizational commitment, and divided the relevant factors affecting organizational commitment into eight categories, including personal characteristics, motivation, job satisfaction, job performance, job stress, job characteristics, team and leadership relationships, organizational characteristics, etc. Each category is divided into different variables, which makes the antecedents of organizational commitment more numerous[6]. On this basis, and then build a variety of organizational commitment factors model: Steers's causality model, Stevens' role perception model, Morris and Sherman's multivariate predictive model, Mowday et al. hired early organizations to form models, Meyer and Allen's influencing factors model[7]. So far, most scholars have summarized the influencing factors of organizational commitment into three dimensions: individual factors, work factors, and organizational factors[8].

Thus, previous studies have not explored deeper individual factors, such as psychological complex factors, among the influencing factors of organizational commitment. According to the basic view of psychoanalysis school, psychological complex is the deep psychological factor that determines most psychological and behavioral activities of individuals ( employees ). As one of the important components of social activities, work activities may undoubtedly be influenced by psychological complex. Therefore, exploring the psychological complex factors that affect organizational commitment and exploring the relationship between other dimensions of organizational commitment and psychological complex factors will help to construct a more complete theoretical model of organizational commitment influencing factors.

\section{Methodology}

\subsection{Sandplay and qualitative research}

In recent years, more and more attention has been paid to the application research of sandplay, which was mainly used for psychological treatment and counseling research in the early stage. With the wide application of sandplay technology in various fields, sandplay is also used as an analysis and evaluation tool for psychological evaluation and diagnosis. Since the image analysis technology and psychoanalytic interview technology inherent in sand table games are effective tools to analyze the individual's deep psychological structure and factors, if they can be used in the study of organizational behavior management, it will help to more clearly and profoundly analyze the individual's behaviors and factors in the organization. In fact, in the past three decades, more and more researchers have begun to apply psychoanalysis to explain organizational dynamics and development management techniques[9]. However, the literature on the study of organizational behavior in China from the perspective of psychoanalysis is rare[10,11],while the literature devoted to psychoanalytic organizational behavior management is less[12]. Kets de Vries[13] once criticized traditional management research: "there are too many management researchers who are limited to a very mechanical view of people in a working environment when they are studying the organization. They only saw the surface phenomenon, but did not see the deep structure. In fact, the behavior of individuals in the organization is rooted in the subconscious, and their behavior is deeply influenced by the individual's subconscious and collective subconscious[14]. Then, it is extremely important to 
analyze various phenomena in organizational behavior management from the perspective of psychological analysis, especially those involving personalized factors.

Qualitative research uses researchers themselves as research tools. In natural situations, various data collection methods ( interview, observation, physical analysis ) are adopted. An activity that carries out an in-depth and holistic inquiry into the research phenomenon, forms conclusions and theories from the original materials, and obtains an explanatory understanding of its behavior and meaning construction through interaction with the research object. Matthew B. Miles[15] proposed qualitative research at least two useful ways to build code. The first one is more inductive. Researchers do not need a pre-built code system before collecting data. After getting the information, let's look at the role and location of the information in the context, as well as the variation of the information. Basically this is the "rooted theory" orientation, which was first proposed by Glaser \& Strauss[16] and has many related developments. This method does not reserve any codes. codes appear gradually when reading materials. It is to shape the collected data into a code system. This kind of code system is more characteristic of these materials. And the image analysis technology and psychoanalytic interview technology of sand table games can obtain a large number of personalized qualitative materials with deep psychological significance. These qualitative materials not only have cognitive and emotional contents subordinate to the level of consciousness, but also have deep psychological contents derived from the individual subconscious and the collective subconscious. If we can combine sand table games with qualitative research, it will be of great help to the research of various disciplines including organizational behavior management. At present, the field of sand disc games applied to qualitative research is mainly limited to the field of psychology. For example, Larissa Lagutina1 and others have taken rooted theory to explore the efficacy and mechanism of sandbox games in the treatment of patients with physical diseases with psychological problems[17], According to the principle of grounded theory, Cheng Hua and others encode the work of the initial sand table for the problem children, and get the subject coding table of the sand table with certain validity and stability[18] by the three level encoding, and the Toshihisa Kawahara appears in the Japanese boys by the case study. The image and image of sand are analyzed[19]. Generally speaking, no matter China still adopts such a research paradigm internationally, there is no report on its application to the study of influencing factors of organizational commitment.

The combination of sandplay and qualitative research is more helpful for us to explore the superficial influence factors, deep influence factors and the relationship between the two under the background of realistic culture. In order to explore the deep psychological factors affecting organizational commitment and provide the basis for theoretical sampling for subsequent qualitative research, this study selected a case of multiple resignation according to intensity sampling[20]. Using sandplay as a tool to conduct psychoanalytic interviews, and then adopting qualitative analysis methods to encode the interview content of the initial sandplay works with the influence factors of organizational commitment as the restricted theme: Coding the complex according to the established structure; For other materials, the concept and category are first formed through open coding. Then, through the spindle coding, establish the connection between various categories; Finally, through the integration and refinement of the interaction relationship between spindle codes through selective coding, the core category of influencing factor mechanism of organizational commitment is finally obtained.

\subsection{Coding logic based on grounded theory}

This paper adopts a three-level coding method to code step by step. When opening coding, firstly analyze the interview text material line by line, and post labels, so that the original text material can be decomposed into independent events.Secondly, the meaning of each label is summarized to lay a foundation for the construction of the initial concept. In the process of constructing the initial concepts, the semantic relations between different concepts are analyzed, which lays the foundation for the next construction of the category. The constructed concepts or categories are classified into one concept according to the synonymous relation, while the parallel relation is classified into several concepts respectively. The subordinate relation will be classified into the higher level concepts ( categories ) 
from the concept or from the category ( Table 2.1).

Table 2.1 Relationship type of coding concept (category)

\begin{tabular}{ll}
\hline Relationship type & \multicolumn{1}{c}{ Definition } \\
\hline Coordinating relation & $\begin{array}{l}\text { Coordinating relation refers to a concept } \\
\text { (category) that is heterogeneous in its } \\
\text { definition, but has a certain degree of } \\
\text { correlation, and thus may be subordinate } \\
\text { to a higher concept. } \\
\text { Synonymous relation refers to that } \\
\text { different concepts (categories) express } \\
\text { the same phenomenon or event. } \\
\text { Owner-member relation is one in which } \\
\text { the extension of one concept (category) } \\
\text { is greater than and includes the full } \\
\text { extension of another concept. }\end{array}$ \\
\hline
\end{tabular}

\subsection{Logic and method of psychoanalysis}

Renowned French philosopher Paul ricoeur believes that from the perspective of hermeneutics, psychoanalysis theory is an interpretation theory generated by encoding a special text based on the human subconscious. Specifically, according to the analytical psychology theory of psychoanalysis school, all kinds of things or situations presented in the individual consciousness world are essentially symbols of the psychological energy or structure of the individual subconscious and the collective subconscious. Sand table game technology is based on this theory. it uses the existence -sandbox situation or sand utensil - presented in the individual consciousness world to symbolize the individual's deep psychology, and then discovers or excavates the deep psychology, and carries on the analysis. Thus, this actually constructs the logic and method of psychoanalysis in the sandbox situation, that is, through the symbolic analysis of thesandbox situation and sand utensils, we can find the superficial factors, complex and the relationship between the sandbox situation and sand utensils.

In terms of concrete operation, the logic and method of psychoanalysis in the sandbox situation is to adopt the technology of sandplay, including the technology of free association, the technology of image dialogue, the technology of interaction and contrast between subconscious and consciousness, etc. According to the Logical route of "Eeality $\longrightarrow$ Sandbox situation

Important childhood or past experiences $\longrightarrow$ Complex "carries on attribution analysis. Also according to the analytical psychology theory of psychoanalysis school, for individuals, the real world time series reflected in the sandbox situation is through the past, present and future, that is, the integrated characteristics of sand table work time.Specifically, it is the individual psychological characteristics or psychological activity characteristics symbolized by a sand utensil or sandbox situation, which may be characterized by its childhood or past period of time, or even though it originated in the past, it still maintains its influence. therefore, these psychological States or psychological characteristics are both past, present and possibly future ( before the change ).

Using the logic and method of psychoanalysis in the sandbox situation, we can find the complex that the sandbox situation represents, the superficial factors related to organizational commitment, and the causal connection between complex and superficial factors.

\subsection{Complex coding method}

According to analytical psychology and object relation theory in psychoanalysis school, the specific object structure in the four-dimensional structure of complex is the characteristic structure linked with the personal experience events that produce complex, and is the symbol that distinguishes one complex from other complex. Therefore, the complex is named and endowed with meaning by the specific object associated with the personal experience event when it is encoded: that is, the concept is named in the way of " object + complex", and the definition of complex as the concept when it is encoded takes the object as the core of the definition; In addition, the complex with the same name belongs to the complex with the same name, such as the mother complex ( Table 2.2 ). 
Table 2.2 Code of organizational commitment's complex factors (omitted)

\begin{tabular}{|c|c|c|c|}
\hline Complex & Content structure & Effect & Original words \\
\hline \multirow[t]{2}{*}{$\begin{array}{l}\text { Mother } \\
\text { complex }\end{array}$} & $\begin{array}{l}\text { Object:mother } \\
\text { Emotion:fear,insecurity } \\
\text { Behavior:lying } \\
\text { Events:relationship with } \\
\text { mother }\end{array}$ & $\begin{array}{l}\text { lying } \\
\text { Without a sense } \\
\text { of security } \\
\text { Fear (of others) }\end{array}$ & $\begin{array}{l}\text { I think, my mom (pause).... } \\
\text { dishonesty, and indeed, } \\
\text { extreme insecurity and fear. } \\
\text { That's it. (Researcher:How } \\
\text { does your mother affect } \\
\text { you?) } s\end{array}$ \\
\hline & $\begin{array}{l}\text { Object:mother } \\
\text { Emotion:freedom,indulgence } \\
\text { Behavior: permissiveness } \\
\text { Events:relationship with } \\
\text { mother }\end{array}$ & $\begin{array}{l}\text { permissiveness } \\
\text { (Self and others) }\end{array}$ & $\begin{array}{l}\text { What I got from my mother } \\
\text { was tolerance, too tolerance. } \\
\text { Find that this kind of } \\
\text { tolerance always to consider } \\
\text { and understand others in the } \\
\text { process, there is no principle } \\
\text { in theprocess. In fact. }\end{array}$ \\
\hline
\end{tabular}

In fact, the above coding for the complex belongs to the content analysis method using a coding method, which is what Stemler S.calls "Prior coding". Based on the existing psychoanalytic theories and concepts, a classification has been established before the data collection is complete, that is, the complex is encoded according to the classification of the object. Due to the oneness of complex coding, the coding table was not prepared in advance, and the research mainly explored the relationship between complex and surface factors, so the statistical characteristics of various complex were not analyzed.

\subsection{Sampling}

Since intensity sampling can find cases that can provide very intensive and informative information for research questions, the study used intensity sampling. According to the intensity sampling, a case of multiple departures was selected: subject n ( Alias ), female, Zhuang, 37 years old, undergraduate culture, married, dean of educational administration of a special education school. $\mathrm{N}$ after graduating from university, he has been engaged in various jobs. from 2004 to 2006, he left his job six times, and the average working time did not exceed three months. The members of family of origin include father, mother and younger brother. they are generally related to family of origin. The new-born families include husbands, who are in harmony with their husbands and rely more on them emotionally.

\subsection{Research Tool}

(1)Sandplay materials: $74 \mathrm{~cm} \times 60 \mathrm{~cm} \times 75 \mathrm{~cm}$ sandbox, clean and delicate beach dry sand in the sandbox, the inner side and bottom surface of the sandbox are sea blue; Includes characters, animals, plants, food, natural elements, civilian vehicles and signs, buildings, homes, communication tools, musical instruments, sports equipment, articles for daily use, military equipment, bright objects and other 1638 sand implements in 14 categories.

(2)Recording tool: One Camcorder, sandpaly process record form, sandbox in-depth interview form of organization commitment' influencing factors.

\subsection{Data collection and analysis}

(1)Research ethics: The researchers patiently introduced the purpose, content and safety of the study to the participants in detail, and promised to keep confidential their personal identification information and video and audio materials. they explained to the participants the requirements for the whole process of the interview to be recorded and obtained their consent.

(2)Producing sandbox work: Firstly, explain the concept connotation and characteristics of employee organizational commitment and its influencing factors to the participants, and give 
examples of employee organizational commitment and its influencing factors to ensure their understanding of relevant concepts. Then, the researchers first introduced sandbox, sand utensil, and the game process in detail to the participants, so that the participants could feel the sand, move the sand, demonstrate to the participants how to use the sandbox, indicate that the participants could freely choose sand utensil, and inform the participants to finish an initial sandbox with " my work unit and I" as the restricted theme within the set play time. The initial sandbox work was carried out around the organizational commitment influencing factors. Researchers sit on the side of the sandbox, and their responsibility is to create a safe and protected space and maintain this sense of security. Before finishing the sandplay, take pictures of the finished original sandplay work, and take pictures from two directions(front, top) and save.

(3)Semi-structured psychoanalysis interview: The participants shared their description of the originalsandboxwork and the full video of the semi-structured psychoanalysis interview afterwards. The interview steps are as follows: After the participants shared their descriptions of the originalsandboxworks, the researchers conducted psychoanalytic interviews based on the outline. The main contents of the semi-structured psychoanalytic interviews included : (1)According to the order of importance, please explain the reasons for letting the original intention work in the unit. (2)What sand bars or situations are present in sandbox related to these factors? (3)Relax first, then look at the relevant sofa or situation, take a free association way, will think of the past growth experience of who or things? (4)Can you describe these people or events in the past growth experience? What emotional reactions, ideas and behaviors did it produce in the past events? If it is found that the subject's content has nothing to do with the influencing factors of organizational commitment and there is a tendency to deviate from the theme, the researchers will remind them to focus on the interview of the theme question and further track the inquiry around the captured information. The interview time is based on information saturation. when the participants said in the interview that there was no more information to present and that it was sufficient, they stopped for one hour.

After the interview, the research team converted the collected recordings into text materials, and again screened them strictly according to the definition and characteristics of organizational commitment influencing factors. The interview materials were used to construct the hypothesis of organizational commitment influencing factor model, which was used as a model for theoretical sampling in subsequent studies.

(4)Validity: The researchers have received professional training in psychological counseling, interview and sandplay, and have at least 300 hours of analytical psychological interview experience. The protected physical space and psychological space conditions set up in the sandplay game technology, as well as the researchers' non-evaluative and accommodating attitudes, can ensure the authenticity of the interview content according to the above settings of analytical psychology theory. In addition, according to the theory of psychoanalysis, the psychological complex information in N's interview information is matched and tested theoretically. Triangulation test[21], after obtaining the consent of the subjects, the important interview information collected and the original family members and new family members of the test were verified by WeChat, and the authenticity test was carried out: Finally, the participant test method[22] was used to feed the results back to the participants, and the participants agreed with the conclusions made by the researchers.

\section{Results}

\subsection{Code Reliability Test}

The interview video and audio information was sorted into a total of 18,679 words in the word text document. The collected data was sorted by qualitative research data analysis software Nvivo11 (Chinese version), according to Glaser, B G. \& Stauss, AL. The step-by-step coding method of "rooted orientation" carries out the induction and relationship construction of concepts and categories, and finally the theme is precipitated. Specific as follows: (1)Set up coding groups. In order to avoid subjective understanding of coding caused by the knowledge structure of coders, two research 
members, both of whom have analytical psychology foundation and have received professional training in sandplay games, form coding teams to carry out data labeling and coding work respectively; (2)Code reliability test. The code takes multiple reciprocations, according to the coded reliability formula proposed by Matthew B. Mile et al. [23]:R = S / $(S+D)$ (where $S$ is the number of mutually agreed codes, and $\mathrm{D}$ is the number of codes that mutually disagree), and the consistency check is performed on the codes between and within the coders. After the final inspection, the reliability test result $\mathrm{R} o$ between the coders was $86.3 \%$, and the reliability test results $\mathrm{R} i$ within the two coders were $88.1 \%$ (Table 3.1), and the $\mathrm{R}$ values were all $>80 \%$. Higher. (3)Establish a research memorandum. In Nvivo11 (Chinese version), a memo is created for the sample, and the coding result of the sample and the modification process are recorded.

Table3.1 Coding reliability

\begin{tabular}{cccc}
\hline Code number & Coder & Ri & Ro \\
\hline I & 1,2 & & 0.612 \\
II & 1,2 & $0.724,0.645$ & 0.784 \\
III & 1,2 & $0.881,0.823$ & 0.863 \\
\hline
\end{tabular}

\subsection{Complex coding}

Analytic psychology holds that personality structure consists of three levels: consciousness ( ego ), individual subconscious ( complex ) and collective subconscious ( prototype ) ( figure 1 ). The complex exists in the individual's subconscious. In a general sense, it refers to the individual's special feeling about a place, a person or something, and is a part of his personal psychology[24]. Complex has its own internal drive, such as a small personality structure that exists independently in the whole personality. it has a very strong influence on controlling our thoughts and behaviors[25].

Through thesandboxgame interview, $\mathrm{N}$ recalled the image of his mother by the free association of D ( problem colleague ). According to N's description, the mother has " dishonesty, and also, in fact, extremely insecure and fearful inside. The characteristics of " ( $\mathrm{N}$ statement ). $\mathrm{N}$ thinks that " because she ( mother) has some ways, I will follow, so I will suffer a lot", " but there is no principle. Finding this kind of tolerance, always thinking about it, always understanding and understanding other people's process, there is no principle, in fact, it is caused, as if other people can understand everything, so how negative things you do are also understandable, that is, so it leads to doing things yourself, sometimes, the principle is not strong. " N's teenage years were tense with his mother, who often quarreled with her and cared little about $\mathrm{N}$. These have formed n's mother complex. His mother complex has the following characteristics: (1) Relationships with women ( especially older women ) are prone to conflict. (2) In the face of difficulties, extreme psychological reactions often occur. (3) In ordinary social activities, negative psychological reactions are often repressed and self - deception.

(4) Self - centeredness, stubbornness, emphasis on self-ability to solve problems, and less acceptance of other people's suggestions; (5) Poor financial management and unplanned economy;

(6) Understanding oneself and others without principle and tolerance, valuing righteousness with light money.

Through further interviews, the content of N's statement also shows the characteristics of father complex ( colleague B is deeply appreciated by $\mathrm{N}$ because $\mathrm{B}$ has the characteristics similar to father ):

(1) Relationships with men are easy to get along with; (2) Introverted, patient and careful in doing things; ( 3 ) Being kind to people, but being social and passive and patient; ( 4 ) Do things conscientiously and responsibly, think ahead, etc. In addition, family of origin's trauma complex also appears, with: (1) Lack of security and loneliness; (2) Attach great importance to the feelings of the opposite sex and strongly need to be loved. (3) Extreme treatment of heterosexual feelings. As well as the complex of leaving the company. (1) When graduating from college, I was deeply hurt by my sudden and passionate resignation, so I was very responsible and serious about my work. (2) I am very disgusted and afraid of narrow emotional views and extreme ways of doing things.

Through induction and coding, four kinds of important psychological complex related to 
organizational commitment are obtained: mother complex, father complex, Original family complex, and resignation complex.

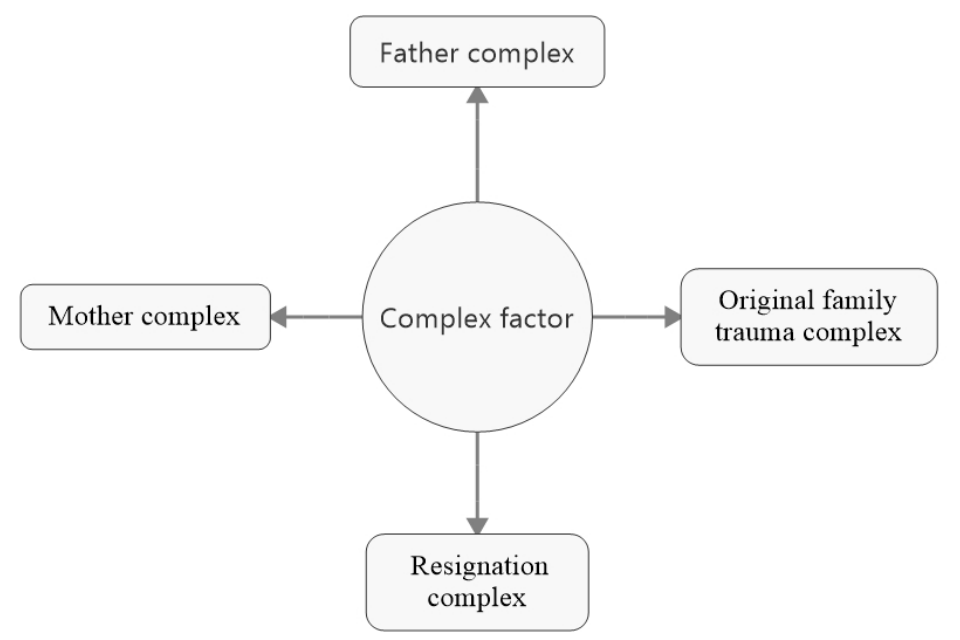

Figure 3.1 Complex factor

\subsection{Level-1 Coding (Open login )}

The first-level coding conceptualizes and categorizes the collected original information. it is a process of " breaking", " crushing" and re-integrating the information, aiming at defining concepts and discovery categories. While collecting data, open coding is carried out. The original data collected in the interview are analyzed word by word. As far as possible, the original words in the text are used as labels to discover the initial concepts from them. 573 lines of original sentences and corresponding initial concepts are obtained. Those who had the cross phenomenon of the initial concepts were merged. Therefore, the research group sorted out and summarized them and extracted 21 concepts and 14 categories. In order to save space, only one representative original sentence and its initial concepts were selected for each category ( Table 3.2 ).

Table 3.2 Causal relations between surface factors(first-level coding) and complexs (omitted)

\begin{tabular}{|c|c|c|c|}
\hline Category & Initial concept & $\begin{array}{l}\text { Sandbox situation and } \\
\text { complex factors }\end{array}$ & Original words \\
\hline \multirow[t]{3}{*}{$\begin{array}{l}\text { Conflict } \\
\text { between self- } \\
\text { growth and } \\
\text { interpersonal } \\
\text { relationships }\end{array}$} & $\begin{array}{l}\text { Interpersonal } \\
\text { barriers; } \\
\text { self-growth }\end{array}$ & $\begin{array}{l}\text { In the sand table situation, } \\
\text { the subjects are nervous } \\
\text { with } \mathrm{D} \text {, and } \mathrm{D} \text { represents } \\
\text { colleagues who have } \\
\text { interpersonal conflicts in } \\
\text { reality;Affected by the } \\
\text { mother complex }\end{array}$ & $\begin{array}{l}\text { In the process of self- } \\
\text { growth, in fact, the } \\
\text { interpersonal relationship } \\
\text { has played a very important } \\
\text { role. }\end{array}$ \\
\hline & $\begin{array}{l}\text { Self-growth } \\
\text { needs lead to } \\
\text { interpersonal } \\
\text { tensions }\end{array}$ & $\begin{array}{l}\text { Tower and mountain } \\
\text { symbolic vision expansion; } \\
\text { Affected by the mother } \\
\text { complex }\end{array}$ & $\begin{array}{l}\text { That is to say, in fact, the } \\
\text { excavation of this river } \\
\text { allows me to stand taller } \\
\text { and look farther, but it } \\
\text { seems to be isolated. }\end{array}$ \\
\hline & $\begin{array}{l}\text { Consciousness } \\
\text { recognizes that } \\
\text { there are } \\
\text { differences } \\
\text { between the } \\
\text { two positions }\end{array}$ & $\begin{array}{l}\text { The two tributaries of the } \\
\text { river symbolize two } \\
\text { positions, and the tributary } \\
\text { of the self-like symbolizes } \\
\text { the position of the } \\
\text { Academic Director. }\end{array}$ & $\begin{array}{l}\text { Researcher: Well, if it's } \\
\text { specific to your work, the } \\
\text { two rivers are like a } \\
\text { mouthful, right? So what do } \\
\text { you think about in reality? } \\
\text { N: Mainly about the work } \\
\text { content. }\end{array}$ \\
\hline
\end{tabular}

Main content of sandbox situation( shown in Figure 3.2 ): During the early production, N planned to build a " mountain" at the " island". Later, due to the isolation of the " mountain" found in the river 
course, he changed the " mountain" into an " island". In the " mountain" shown in figure 1, he saw a " mountain" and built another " tower" on the mountain. "Mountain" and " tower" are expressions of N's desire to expand his field of vision. Self-image ( women sailing boats ) in the river channel " riding the wind and breaking the waves" is a symbol of the choice and dilemma of practical work. The red arrow is in the direction of the river, and the river branch is a symbol of two kinds of work positions where $\mathrm{N}$ is both a body and a body. : Dean of educational administration and teacher, $\mathrm{D}$ is a colleague who represents the problem of interpersonal conflict with him in reality, B is a colleague whom he appreciates ( deputy director of the office ), $\mathrm{H}$ is the unit leader who controls the whole situation, and children in the unit ( school ), etc.

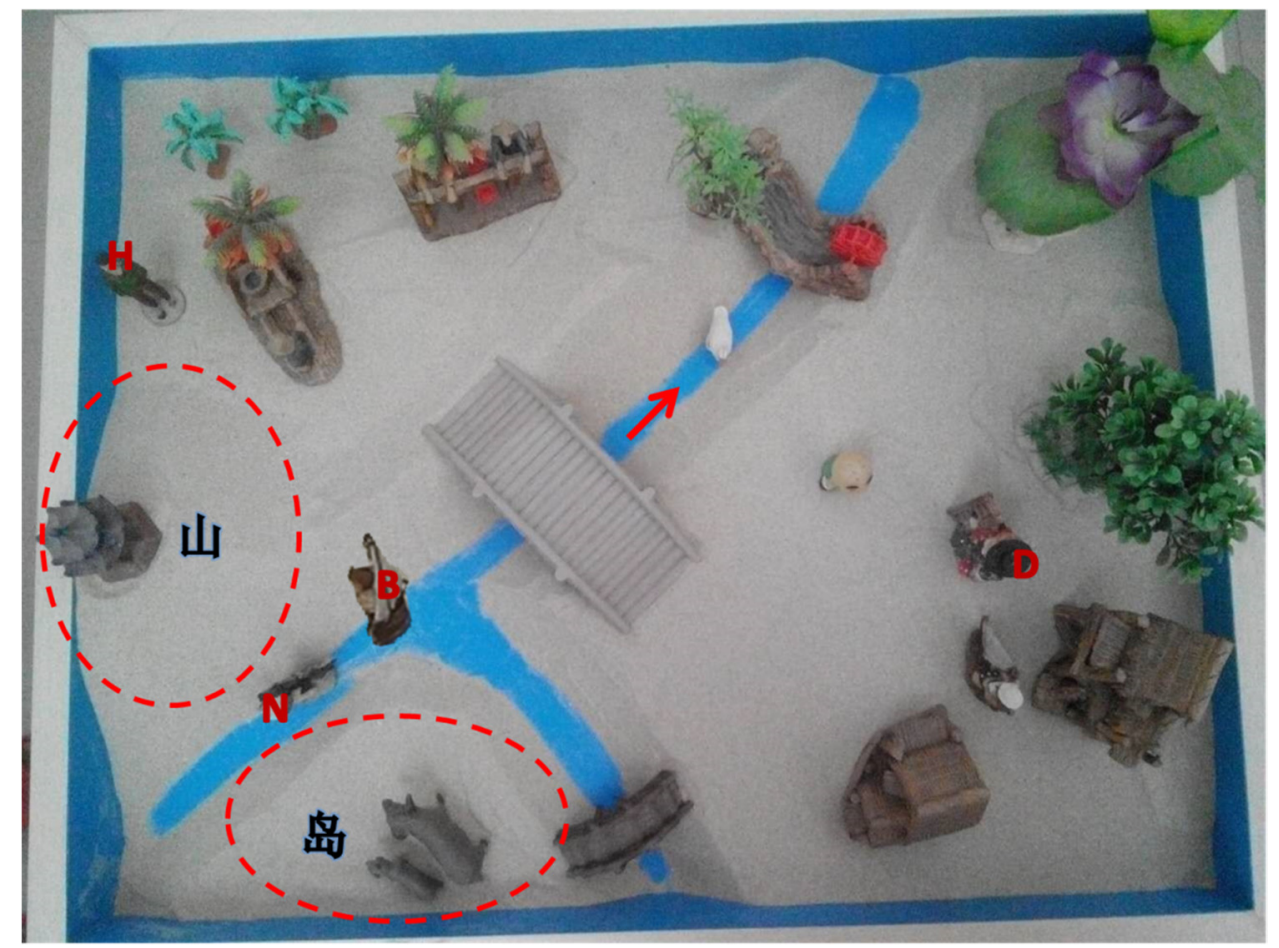

Figure 3.2 The initial sandbox work of $\mathrm{N}$

\subsection{Level-2 coding (Relational login)}

Level-2 coding is the second step in coding analysis, which is more directional, selective and conceptual than line - by - line, sentence-by-sentence and segment-by-segment coding[26]. Through cluster analysis, various connections between categories are discovered and established to form more systematic and general categories. Based on the independent categories formed by open coding, this study re-integrates them according to their internal connections and logical relationships, and finally forms 8 main categories (Table 3.3 ).

Table 3.3 Main categories of level-2 coding of surface factors

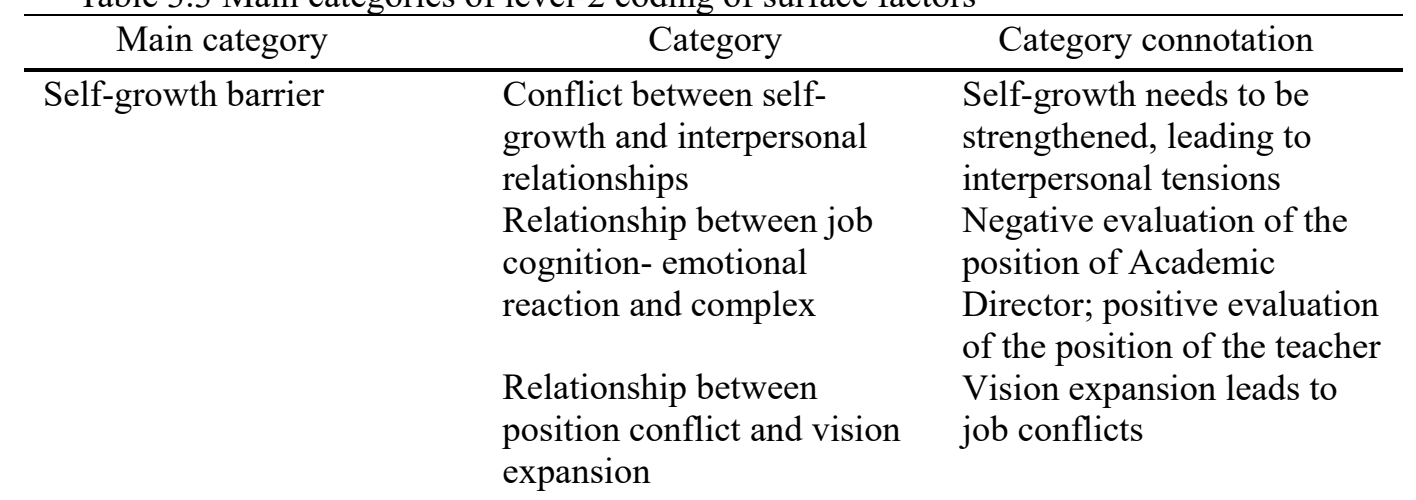




\author{
Psychological quality of \\ work \\ Thought and knowledge \\ field \\ Family support
}

Income

Leadership support

Working relations

Organizational atmosphere
Cognitive Differences between Self-consciousness and Subconsciousness

Relationship between interpersonal relationship and complex Improve the psychological quality of work expand vision

The emotional support of the new family is important Indifferent feelings of the original family

Heterosexual support is important

Income is secondary

Leadership support is secondary Working relationship is secondary Organizational atmosphere is secondary
Consciousness and subconsciousness are contrary to the work content and nature of the position, Consciousness and consciousness of the target are consistent Interpersonal relationship conflicts in the position of Academic Director The courage to face and solve difficulties at work Work is to stand taller and farther, not narrow After marriage, the family can give love to self During adolescence, parents' love for me was deprived, and communication barriers led to feelings of indifference.

Desire to get male love, it is very painful after losing love

Do not pay attention to income

Don't worry if the leader values myself.

Working relationship is unimportmant

The organizational atmosphere has a certain impact on myself, but the key to seeing my ability to work

\section{5 level-3 Coding(Core Login)}

Level 3 coding is a structure naturally appearing between level 2 coding. The process of mining the core categories through the main categories and linking the core categories with other categories to analyze the relationship between them includes: Identify core categories that are sufficient to control all categories, develop story lines to depict the overall behavior phenomenon, and continue to develop categories to make them more detailed and subtle. Based on the continuous exploration of the main categories and the intention of this study, six core categories and the structure of organizational commitment deep-seated factors composed of four types of complex are found(Figure 3.3).

Because this study adopts a qualitative analysis of a single case, the purpose of this study is to explore the deep psychological factors that affect organizational commitment and provide a theoretical basis for subsequent qualitative research. Therefore, based on the results of this qualitative analysis of this case and through sorting out research memos, a mechanism model of organizational commitment influencing factors with psychological complex as a deep factor has been preliminarily established (Figure 3.3). The six core categories of " self - growth", " maintenance of family", " economic income", " working relationship", " leadership support" and " organizational atmosphere" together form a mechanism model of organizational commitment influencing factors with psychological complex as a deep factor. In figure 3.3, Line width represents the weight of influence ,the dotted line represents partial influence ,the solid line represents decisive influence. 


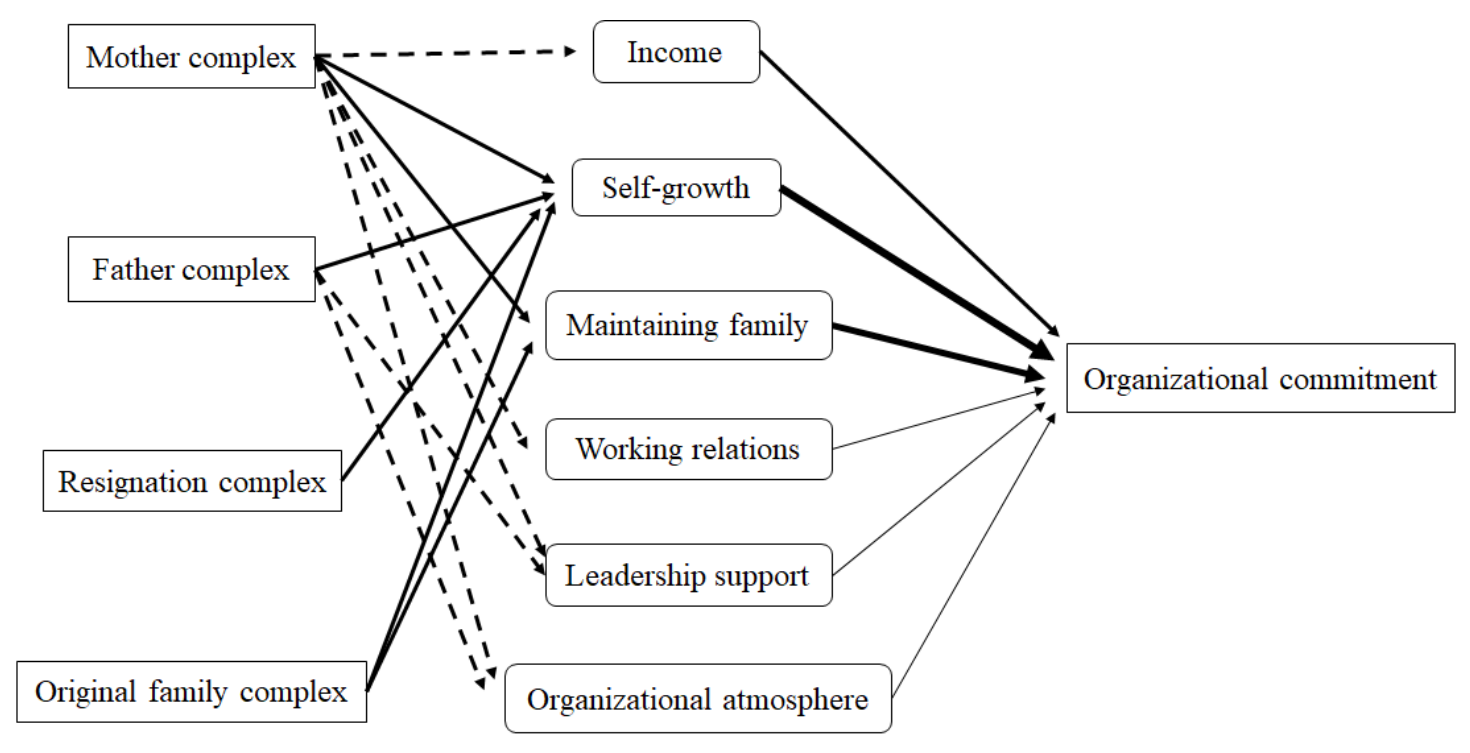

Complex factor Surface factor

Figure 3.3 Organizational Commitment Influencing Factors Mechanism Model

\section{Discussion and Conclusion}

Although the mechanism model established in figure 3.3 may not cover more deep factors and may be rough in classification of surface factors, the model still contributes a lot: First of all, the psychological complex has never been found in previous studies to be actually a deep factor affecting organizational commitment. Secondly, at least the case reveals that there are differences in the influence of deep factors on superficial factors: for example, the influence of mother's complex on the two dimensions of self-growth and family maintenance, the influence of father's complex, family of origin's trauma complex and separation complex on the dimension of self - growth, and the influence of mother's complex and family of origin's trauma complex on the dimension of family maintenance are all decisive. Dimensions such as economic income, working relationship, leadership support and organizational climate are all partially influenced by the mother complex, while dimensions such as leadership support and organizational climate are also partially influenced by the father complex. The model of the relationship between the superficial factors and complex factors of organizational commitment and the two-dimensional model of complex factors of organizational commitment are the most important components of the mechanism model of influencing factors of organizational commitment. this model confirms the deep psychological mechanism that affects organizational commitment from the perspective of psychoanalysis, provides a theoretical basis for the construction of organizational behavior management strategies for individuals, provides a preliminary theoretical framework for subsequent related research, and also provides a theoretical basis for organizations to retain talents.

The deficiency of the research lies in: It is also necessary to use theoretical sampling method to explore more cases until the theory is saturated. Only in this way can the theoretical model be constructed to comprehensively cover the categories of possible psychological complex and surface factors, which is more convincing and more extensive.

\section{References}

[1] Becker,H.Notes on the concept of commitment.American Journal of Sociology, 66,1960.

[2] Ma,F.,Kong,F.J\&Sun,H.L. Theoretical Review On Organizational Commitment. Information science, 28 (11):1743,2010.

[3] Zhang,M.Z. Influence Factors And Outcome Variables Of Organizational Commitment. Fujian Forum (Humanities and Social Sciences Edition),122-123,2006. (In Chinese) 
[4] Yue, G.A., Yin, H.Y. \& Wang, X.Z. Research Review On Organizational Commitment. Applied Psychology, 12 (1):84,2006. (In Chinese)

[5] Mowday R,Porter \& L,Steers R. Employee-organization link ages:The psychology of commitment,absenteeism, and turnover.NewYork:Academic Press, 1982.

[6] Mathieu J E,Zajac D M. A review and meta-analysis of the antecedents,correlates and consequences of organizational commitment.Psychological Bulletin,108:171-194,1990.

[7] Zhang,Q.L.\&Zhang,H.F. Model Study Of Organizational Commitment.Human Resource Management,7:223-224,2011 (In Chinese)

[8] Ma,L.\& Wang,Y. Review And Trend Of Organizational Commitment Research. Commercial Time, 22:78,2012.

[9] Levinson,H. Psychoanalytic theory in organizational behavior: handbook of organizational behavior. Englewood Cliffs,New Jersey:Prentice Hall.1987.

[10]Ma,Ch.\&Ye,J.L. Psychoanalysis And Public Administration: From Freud To Diamond. Journal Of Wuhan University: Social Science Edition, 54(1): 93,2001.

[11]Xu.B. Adaptive Research Of Theory And Method Of Psychoanalysis On Bureaucratic Organization. Journal Of Fujian Provincial Party School, 311(11):45,2006. (In Chinese)

[12]He,L.S. Research On The Methods Of Organization Consultation.Yantai: Shandong University,2006 (In Chinese)

[13]KETS DE VRIES,M.F.R \& MILLER,D. Interpreting organizational texts.Journal of Management Studies,24(3):233-247,1987.

[14]DIAMOND.VI.ALLCORN S.\& HOWARD STEIN. The surface of organizational boundaries:a view from psychoanalytic object relations theory. Human Relations, 57(1):31-53,2004.

[15] Matthew B. Mile,A. Miehael Huberman.\&Zhang,F.F. Qualitative Data Analysis: Methods And Practices (Second Edition), ChongQing: ChongQing University press, 83,2015.

[16]Glaser,B G.,\& Stauss,A.L. The discovery of grounded theory:Strategies for qualitative research.Chicago:Aldine,135, 1967.

[17]Larissa Lagutina,David Sperlinge \& Alexander Esterhuyzen. Addressing psychological aspects of physical problems through sandplay: A grounded theory study of therapists' views. Psychology and Psychotherapy: Theory, Research and Practice,86:105-124,2013.

[18]Cheng,H.,Zhang,X.L.\& Wu,M.R. Establish Children Initial Sandtray Topic Feature Encoding Table Based On Grounded Theory.Journal of Guangdong Medical College, 29 ( 5): 494,2011 (In Chinese)

[19]Kawahara,Toshihisa. Relating in a Global Community. Proceedings of the International Conference on Counseling in the 21st Century, Sydney, December 29-31. Washington: The Educational Resourses Information Center,1998.

[20]Chen,X.M. Qualitative Research Methods And Social Science Research.Beijing: Education Science Press, 106,2000. (In Chinese)

[21]Chen,X.M. Qualitative Research Methods And Social Science Research.Beijing: Education Science Press, 402,2000. (In Chinese)

[22]Chen,X.M. Qualitative Research Methods And Social Science Research.Beijing: Education Science Press,405,2000. (In Chinese)

[23] Matthew B. Mile,A. Miehael Huberman.\&Zhang,F.F. Qualitative Data Analysis: Methods And Practices (Second Edition), ChongQing: ChongQing University press, 91,2015.

[24] SingerT \& Kimbles SL. The Cultural Comlex:Contemporary Jugnian Perspectives on Psyche and Society Psychology.Printed in Great Britain: Psychology Press.185,2004.

[25] Yin,L.Consciousness, Individual Unconsciousness And Collective Unconsciousness: A Brief Analysis Of The Psychological Structure Of Analytical Psychology. Social Science Research,2:62-64,2002. (In Chinese)

[26]Glaser,B.G. Theoretical Sensitivity: Advances in the Methodology of Grounded Theory.Mill Valley, CA: Sociology Press, 1978. 